\title{
DECISÕES CONFLITIVAS NA LIBERAÇÃO DOS TRANSGÊNICOS NO BRASIL
}

$\mathrm{A}$ aplicação da engenharia genética, principal ferramenta da moderna biotecnologia, à agricultura vem provocando profundas controvérsias quanto a possíveis riscos à saúde e ao meio ambiente, assim como sobre suas implicações nos âmbitos político, socioeconômico e ético. No Brasil, apesar da existência de significativos instrumentos legais e instâncias decisórias específicas sobre a questão, práticas não condizentes com a legislação em vigor geraram uma acirrada polêmica entre diversos atores envolvidos, como cientistas, agricultores, ambientalistas e representantes do governo. Tal polêmica foi proveniente, em grande parte, da atuação da Comissão Técnica Nacional de Biossegurança (CTNBio) e dos Ministérios, a quem a legislação atribuiu responsabilidade clara sobre a temática.

Este artigo tem como referência esse contexto e foi realizado com o intuito de desvendar algumas das razões capazes de justificar as decisões assumidas pelas principais instâncias responsáveis pela biossegurança no país, no período de 1995 a 2002.

\section{MATERIAL E MÉTODOS}

Analisou-se o tratamento dado a solicitações para liberação ambiental de transgênicos pela CTNBio. A discussão centrava-se nos questionamentos suscitados pelos procedimentos de biossegurança utilizados na aprovação das primeiras liberações ambientais, experimentais e comerciais.

A documentação coletada sobre os procedimentos seguidos pela CTNBio - enquanto principal instância decisória na avaliação do uso dos transgênicos - referente ao período de 1995 a 2002, foi de fundamental importância para elucidar a origem dos conflitos gerados pela sua atuação, nem sempre em consonância com a legislação vigente. Foram reunidos dados sobre os processos encaminhados à comissão e autorizações concedidas para liberações experimentais no meio ambiente e, no caso da soja, para fins comerciais.

A rede mundial de computadores (Internet), particularmente os sites dos Ministérios, revelou-se também uma fonte importante para avaliar, em parte, o tratamento con- 
ferido à temática. A atuação dos órgãos ministeriais responsáveis por fiscalizar a aplicação dessa tecnologia foi objeto de especial atenção.

As matérias divulgadas na imprensa revelaram-se uma fonte profícua e indispensável para uma permanente atualização, com fatos, das posições e práticas conflitantes em relação à biotecnologia agrícola. Como observa Wolf (1997), temas de significativa importância pública têm que ser abordados pela imprensa escrita e com menor grau de fragmentação que a mídia falada. Enquanto "quarto poder", como habitualmente é qualificada, adquire legitimação na medida em que favorece a expressão de idéias diferentes e, inclusive, exerce um poderoso contraponto ao que Hobsbawn (1995) denomina de "segredos dos governos".

A consulta ao conteúdo de determinadas ações acolhidas pelo Ministério Público, pela farta e consistente argumentação com que este órgão fundamentou seus pareceres, acrescentou elementos substantivos para caracterizar as posições conflitantes em torno da questão. Da mesma forma, o acesso às transcrições das Audiências Públicas realizadas por diversas comissões da Câmara dos Deputados sobre o assunto constituiu valioso subsídio.

Recorreu-se ainda aos textos e informativos divulgados por organizações da sociedade civil que mais se destacaram - entre as integrantes da campanha "Por um Brasil Livre de Transgênicos" - na defesa da legislação pertinente ao campo da biossegurança, particularmente o Instituto Brasileiro de Defesa do Consumidor - Idec e o Greenpeace. Nesse sentido, um instrumento privilegiado foi o boletim eletrônico disponibilizado pela campanha, desde 1999, com a principal finalidade de "disseminar idéias e informações sobre os impactos e riscos dos Organismos Geneticamente Modificados - OGM no meio ambiente, na saúde do consumidor e na agricultura".

O valioso acervo contido em artigos, editoriais e notícias publicados na grande imprensa possibilitou o acesso, entre outras informações, a declarações e atuação de autoridades governamentais, de representantes de setores empresariais, de associações corporativas, de organizações não-governamentais e análises da produção agrícola e de sua comercialização. Alguns dos principais jornais utilizados foram O Estado de S.Paulo e Valor Econômico.

\section{A BIOSSEGURANÇA NO BRASIL}

A lei brasileira de biossegurança (Lei n. 8.974) definiu as diretrizes para o controle das atividades e dos produtos originados pela biotecnologia moderna ou tecnologia de DNA recombinante. Estabeleceu

normas de segurança e mecanismos de fiscalização no uso das técnicas de engenharia genética na construção, cultivo, manipulação, transporte, comercialização, consumo, liberação e descarte de organismo geneticamente modificado $(O G M)$, visando proteger a vida e a saúde do Homem, dos animais e das plantas, bem como o meio ambiente (grifo nosso).

O Decreto n. 1.752/95, que regulamentou a Lei n. 8.974, dispôs sobre a competência e composição da Comissão Técnica Nacional de Biossegurança - CTNBio.

Mais recentemente, o governo editou a Medida Provisória n. 2.191-9, de 23 de agosto de 2001, na qual foi corrigida uma questão legal que envolvia a comissão, uma vez que os artigos relacionados à sua criação na Lei de Biossegurança tinham sido vetados na época. Com essa MP, o governo buscou assegurar a legitimidade jurídica da comissão, conferindo-lhe novas atribuições e fortalecendo-a enquanto fórum privilegiado de tomada de decisão. A CTNBio, além de continuar emitindo pareceres técnicos conclusivos, passava a exercer funções que anteriormente pertenciam aos Ministérios.

De acordo com o decreto que regulamentou a Lei de Biossegurança, compete à CTNBio:

$$
\begin{aligned}
& \text { propor a Política Nacional de Biossegurança; acompanhar } \\
& \text { o desenvolvimento e o progresso técnico e científico na } \\
& \text { Biossegurança e em áreas afins, objetivando a segurança } \\
& \text { dos consumidores e da população em geral, com permanen- } \\
& \text { te cuidado à proteção do meio ambiente. }
\end{aligned}
$$

Todas as atividades de manipulação, transporte, importação, comercialização e liberação no meio ambiente de organismos geneticamente modificados, ou derivados, devem ser autorizadas previamente pela comissão.

A comissão era composta por especialistas de notório saber científico e técnico em biotecnologia, tendo representante de cada uma das áreas: humana, animal, vegetal e ambiental. Conta também com representação dos Ministérios da Ciência e Tecnologia, da Saúde, do Meio Ambiente, da Educação e das Relações Exteriores, bem como do Ministério da Agricultura e do Abastecimento, tanto da área vegetal quanto da animal. Os órgãos de Defesa do Consumidor e de Proteção à Saúde do Trabalhador, assim como o setor empresarial de biotecnologia, têm também representação na comissão.

Em síntese, a regulamentação brasileira relativa à engenharia genética e a seus produtos, para alguns autores 
como Fontes et al. (2000), era considerada criteriosa, abrangente e capaz de atender às necessidades/interesses do país. Essa avaliação parecia partilhada por diferentes órgãos do governo responsáveis pelo seu cumprimento, mas restava confirmar se a prática adotada era condizente com tais atributos.

A criação da CTNBio, em 1995, foi vista como um avanço para assegurar que a tecnologia dos transgênicos fosse avaliada de acordo com os conhecimentos técnicocientíficos. No entanto, ao longo de sua atuação enquanto órgão responsável pelo controle dessa tecnologia, a comissão foi sendo questionada.

No site da comissão na Internet, percebiam-se sinais de que os problemas já começavam com os referenciais utilizados. A comissão definia a biossegurança como "uma ciência surgida no século XX", cujo fundamento básico era "assegurar o avanço dos processos tecnológicos e proteger a saúde humana, animal e o meio ambiente." Assegurar o avanço dos processos tecnológicos não pode ser tarefa da biossegurança, pois, em decorrência da utilização de critérios adequados de avaliação, pode limitar, retardar ou até impedir tal avanço.

A comissão não conseguiu desempenhar uma das atribuições que lhe foi conferida pelo Decreto n. 1.752, de 20 de dezembro de 1995: propor a Política Nacional de Biossegurança. Durante esses dez anos de sua existência, tal proposta não foi elaborada e tampouco foram estabelecidos critérios mínimos para avaliação das solicitações de liberação ambiental dos OGMs, tais como as dimensões consideradas aceitáveis para uma área experimental. As áreas liberadas nos diversos processos de solicitação não permitiam entender o objetivo das empresas requerentes, assim como a lógica utilizada pela comissão no seu deferimento. Essas áreas oscilavam entre valores de rigor numérico surpreendente, como $0,006,0,010496,0,030016$, 0,025088 hectares, até uma liberação de 110 hectares, em que a conotação "experimental" ficava sob suspeita.

As dimensões solicitadas para experimentação não pareciam ser motivo de questionamento pela comissão, como pode comprovar-se no processo n. 675/98-51, que propôs uma extensão de nada menos que $1.869,78$ hectares. Esse processo foi indeferido, mas do conjunto de justificativas para o indeferimento não constou nenhuma referência ao tamanho inadequado da área.

Uma liberação de 110 hectares, segundo estimativas, pode produzir em torno de 33.300 .000 plantas. Com dimensões de tal porte, é difícil encontrar razões para argumentar que não se tratasse de uma liberação para fins co- merciais, sendo dispensável a declaração dessa intenção. Nesse processo, a requerente Monsanto informa à comissão que

os procedimentos e cuidados a serem utilizados para produção de sementes de soja Roundup Ready serão os mesmos adotados para produção de sementes de soja não transgênica (CTNBIO, 2002),

desconsiderando, explicitamente, a necessidade de adoção de medidas específicas de biossegurança.

Finalmente, no mesmo processo, a empresa Monsanto acrescenta que a produção resultante desse experimento seria: "inicialmente, armazenada na própria Estação Experimental de Morrinhos - GO, sendo posteriormente destinada às áreas de produção" (CTNBIO, 2002). Como se evidencia, a empresa não omite sua intenção de, na vigência de uma moratória, encaminhar o que a princípio seria um experimento para as áreas de produção. A comissão, ao examinar o processo para emitir o parecer, ignorou essas discrepâncias.

Em relação à empresa solicitante, o relatório final da Comissão de Defesa do Consumidor, Meio Ambiente e Minorias da Câmara dos Deputados alertava:

Vale registrar que todos os ensaios autorizados pela CTNBio em grandes áreas, o são para um mesmo grupo econômico: Monsanto. As áreas experimentais autorizadas para as demais empresas e para as instituições públicas são significativamente menores, todas dentro de padrões aceitáveis pelo bom senso e, salvo melhor juizo, pela práxis científica (CÂMARA DOS DEPUTADOS, 2000).

Algumas liberações para “demonstração” também eram questionáveis, entre outros motivos, pela dificuldade de fiscalização, devido a sua dispersão em Estados e municípios. Diversos processos autorizaram liberações de milho transgênico no meio ambiente, para diferentes fazendas, com o objetivo de demonstrar a "nova tecnologia" aos agricultores e técnicos, bem como avaliar o desempenho de linhagem geneticamente modificada. As liberações com esse propósito incluíram, por processo, de 20 a 40 diferentes fazendas, sítios, granja, campo demonstrativo de cooperativa, sociedade rural, fazenda experimental de cooperativa, fundação para assistência agropecuária e pesquisa, centro tecnológico de cooperativa, sociedade agrícola e cooperativa agropecuária - localizados em diversos municípios.

Esse conjunto de liberações, até onde se tem conhecimento, não foi alvo de qualquer plano especial de fiscali- 
zação e, em conseqüência, podem ter contribuído para a disseminação de sementes transgênicas no país, proibidas por decisão judicial.

Sobre essas liberações "demonstrativas", o relatório anteriormente referido concluía que essa prática

tangencia a irresponsabilidade, a leviandade. Uma comissão que tem a confiança da sociedade, que a institui como guardiã da biossegurança, a quem confia o papel de zelar por sua segurança, cede à sedução das empresas de biotecnologia e permite-lhes fazer demonstração de uma tecnologia não autorizada e ainda pendente de avaliações e estudos que permitam concluir por sua liberação ou não. Só faz sentido uma CTNBio que assuma o papel de juiza, que julgue em função dos aspectos técnicos conclusivos. A sociedade delegou-lhe a função de juiza da biossegurança, não de promotora da biotecnologia (CÂMARA DOS DEPUTADOS, 2000).

Outro tipo de liberação considerada problemática, como se constata numa solicitação do Ministério da Agricultura - Comunicado n. 113, publicado em 3 de julho de 2000 para que a comissão

em caráter de urgência, em virtude da quebra da safra de milho no país, emita parecer técnico conclusivo sobre a segurança alimentar para animais, dos eventos/hibridos de grãos de milho geneticamente modificado disponiveis no mercado mundial para comercialização.

A solicitação obteve parecer favorável e as providências para a importação foram imediatamente adotadas, embora contrariassem a Lei de Biossegurança que determinava que

produtos contendo OGM, destinados à comercialização ou industrialização, provenientes de outros países, só poderão ser introduzidos no Brasil após o parecer prévio conclusivo da CTNBio e a autorização do órgão de fiscalização competente, levando-se em consideração pareceres técnicos de outros países, quando disponiveis (CÂMARA DOS DEPUTADOS, 2000).

Entretanto, no parecer favorável emitido pela comissão não há qualquer alusão à necessidade dessa autorização, embora as empresas responsáveis pelo transporte e processamento final do grão não dispusessem de Certificado de Qualidade em Biossegurança - CQB, exigência estabelecida na Lei de Biossegurança para qualquer entidade nacional, estrangeira ou internacional, que desenvolva atividades com OGMs e seus derivados (CÂMARA DOS DEPUTADOS, 2000).
O relatório aponta, ainda, a ocorrência de falhas nos cuidados com a segurança alimentar. Analisando a correspondência entre a CTNBio e o Departamento de Agricultura Americano, a fim de obter informações sobre as linhagens de milho incluídas na solicitação, o estudo conclui que, embora a comissão tenha autorizado a importação de sete diferentes linhagens de milho, apenas em três delas apresentavam-se documentos que atestavam a segurança alimentar.

Soma-se a isso o fato de que, nessa época, já havia uma decisão judicial proibindo a liberação dos transgênicos. Em conseqüência, mais uma vez, decisões em desacordo com a legislação vigente acabaram por provocar uma série de ações judiciais, tentando evitar a importação desse milho, numa contínua realimentação da polêmica instaurada.

A atuação dos Ministérios é fundamental no cumprimento da legislação de biossegurança. Além da responsabilidade pela fiscalização, embora a CTNBio fosse a responsável por elaborar o parecer técnico sobre os cultivos transgênicos, a decisão final caberia aos Ministérios da Agricultura, Meio Ambiente e Saúde. Essa fiscalização, no entanto, não ocorreu de maneira satisfatória. Nenhum dos Ministérios cumpriu adequadamente o papel previsto na lei.

O Ministério da Saúde mostrou-se omisso, no que tangia a suas atribuições legais sobre os transgênicos. A Agência Nacional de Vigilância Sanitária - Anvisa, além de eximir-se de sua função fiscalizadora, não tomou providências diante das inúmeras denúncias de entidades, como o Idec e o Greenpeace, sobre a comercialização de diversos produtos com ingredientes transgênicos no país.

Como exemplo, pode-se mencionar a lei conhecida como Lei dos Agrotóxicos, de 1989, aplicada também aos organismos geneticamente modificados para adquirir característica de agrotóxico, como no caso do milho Bt. Entretanto, a Anvisa só adotou as medidas cabíveis quando instada pela Justiça, em virtude de uma liminar obtida, em abril de 2001, por procuradores da República, determinando a suspensão de todas as autorizações para liberações experimentais de transgênicos com características agrotóxicas.

Logo após a decisão judicial, a Anvisa, juntamente com o Ministério da Agricultura e o Ibama, estabeleceu parâmetros para elaboração de uma proposta de critérios para o fornecimento do Registro Especial Temporário - RET, que deveria ser emitido pelo Ministério da Agricultura (Secretaria de Defesa Agropecuária), pelo Ibama e pela própria Anvisa. O RET não foi exigido em nenhuma das autorizações que a CTNBio havia concedido até aquele momento (CAMPANHA..., 2001). 
A deficiência no controle e monitoração das plantas transgênicas foi expressa, de forma clara, pelo responsável da Divisão de Controle do Trânsito e Quarentena Vegetal - DTQ, do Ministério da Agricultura. Indagado sobre os procedimentos técnicos adotados por esse Ministério para identificar se um produto é geneticamente modificado ou não, afirmou que o mesmo não estava tecnicamente aparelhado para essa identificação, dependendo de declaração do exportador a respeito (ZAHLER, 1997). Esse cenário permaneceu inalterado até 2001, quando Zahler, em comunicação pessoal, explicava que, em sua opinião, faltou uma legislação complementar à legislação de biossegurança, pois a lei estabeleceu as competências dos Ministérios para a fiscalização sem fixar um período para a formação de uma infra-estrutura compatível com a execução dessa tarefa.

Em audiência pública na Câmara dos Deputados, o diretor do Programa Nacional de Conservação da Biodiversidade e de Recursos Genéticos/Ministério do Meio Ambiente reconheceu que existiam deficiências em todos os órgãos de fiscalização, afirmando que "Não se consegue, no campo, distinguir o que é e o que não é transgênico" (BRASIL, 2001).

A própria CTNBio admitia que a fiscalização dos organismos geneticamente modificados no país era deficiente e que algumas empresas e laboratórios desrespeitavam as normas de biossegurança (CTNBIO..., 2001). No entanto, o reconhecimento não era suficiente, sendo necessário adotar medidas que modificassem esse quadro ou interrompessem as liberações até que fosse implementada uma rotina eficaz de fiscalização. Afinal, o governo, através de seus órgãos competentes, liberou sistematicamente testes com plantas transgênicas, perfazendo uma área de 943,88 hectares (VIGNA, 2001). Numa estimativa feita no final de 2001, chegou-se a aproximadamente 1.300 hectares liberados.

Como resultado, foram-se delineando, ao longo dos últimos anos, as dimensões da irresponsabilidade no tocante ao conjunto de ações capazes de garantir a condução criteriosa de um processo marcado pela controvérsia. As conseqüências da indefinição de critérios constatada nas liberações concedidas pela CTNBio, assim como da atuação dos Ministérios, ao se eximirem em intervir num cenário que poderá resultar em graves conseqüências para o país, adquiriam total e irrefutável concretude, provocando grande tumulto entre os atores envolvidos e uma farta profusão de artigos e editoriais na imprensa.

Embora não se conheça o real volume da soja clandestina cultivada - o que reflete o descontrole sobre a questão pelos órgãos responsáveis por seu encaminhamento -, observa-se que todas as fontes apresentam números extremamente altos. Não existe certeza da origem dessa soja: se contrabandeada da Argentina, se disseminada pelas empresas à revelia do governo, ou mesmo com o seu aval, diante das inúmeras liberações para "demonstração", como mencionado anteriormente.

Foi notório o empenho demonstrado pelo Ministério da Agricultura na liberação de um alimento controverso e, especialmente, sob moratória judicial. O próprio ministro da pasta em 2001 assegurava, numa entrevista, que a autorização para comercialização dos transgênicos sairia na semana seguinte. Chegou, inclusive, a cogitar a possibilidade de liberar a soja transgênica à revelia da decisão judicial (PRATINI..., 2001a).

Poucos dias depois da entrevista, os jornais noticiaram os bons resultados da empresa Monsanto, no ano de 2001 (LUCRO..., 2001). Diante dessas incisivas afirmações, o Ministério Público entrou na Justiça com uma denúncia contra o ministro, que o levou a recuar, alegando a existência de pendências judiciais (PRATINI..., 2001b). Tal episódio teve repercussões negativas no preço das ações dessa empresa (MONSANTO..., 2001).

A Embrapa, na época da solicitação da Monsanto para a liberação comercial da soja transgênica, pronunciou-se favoravelmente, explicitando seu apoio ao uso e à desregulamentação da soja resistente ao glifosato, por carta enviada por seu presidente à CTNBio e anexada ao processo de liberação da soja (CPR n. 233/1998, SE-PADCT/ GAB n. 369). É incompreensível que um órgão do Ministério da Agricultura se pronunciasse, de forma tão contundente, diante de decisão dessa complexidade.

O Ministério do Meio Ambiente, apesar de não ter exercido adequadamente sua tarefa de fiscalização, foi o único que tentou adotar uma posição independente na avaliação dos transgênicos. No Fórum Nacional de Secretários da Agricultura, o ministro, reconhecendo que os transgênicos ofereciam impactos ambientais ainda desconhecidos, alertava para a importância do cumprimento, pelas empresas, das exigências legais de licenciamento ambiental. E ressaltava: "não se pode visar apenas o atendimento de interesses econômicos imediatistas" (MINISTRO..., 2000).

O Ministério teve também participação relevante no impedimento de liberação comercial da soja RR. O Ibama juntou-se, embora posteriormente, ao processo judicial impetrado pelo Idec e o Greenpeace. No entanto, para evitar conflitos entre setores governamentais, acabou solicitando sua retirada da ação. De qualquer maneira, é inegável o 
peso político que teve sua inserção momentânea, não apenas como fator de reforço ao questionamento técnico apresentado pelas organizações não-governamentais, mas também por colocar em evidência os conflitos existentes dentro das diferentes esferas do governo envolvidas na questão.

O Ministério da Ciência e Tecnologia, abrigando a CTNBio e com poder de nomeação da maioria dos membros da comissão, manteve sempre uma posição de apoio irrestrito ao trabalho desenvolvido pela comissão e favorável à liberação dos transgênicos.

\section{O CASO EMBLEMÁTICO DA LIBERAÇÃO COMERCIAL DA SOJA}

Além dos questionamentos relativos ao elevado número de liberações experimentais sem critérios claros, a comissão sofreu também severas críticas por ocasião da primeira solicitação, no Brasil, para liberação do cultivo, em escala comercial, da soja Roundup Ready, encaminhada pela Monsanto. A CTNBio emitiu um parecer favorável, atestando a ausência de risco ambiental e/ou para saúde humana, sem exigir o EIA e seu respectivo Relatório de Impacto no Meio Ambiente - Rima.

O comunicado n. 54 expressa, de forma contundente, sua avaliação sobre a soja Roundup Ready:

A CTNBio concluiu que não há evidências de risco ambiental ou de riscos à saúde humana ou animal, decorrentes da utilização da soja geneticamente modificada em questão,

esclarecendo, ao final, que aquele ato constituía um "parecer conclusivo de caráter técnico do ponto de vista da biossegurança (BRASIL, 1998, p. 56).

Evidentemente, a CTNBio deixou de observar a importante premissa de que a não comprovação de riscos não implica necessariamente a ausência dos mesmos, além de não aplicar o consagrado Princípio da Precaução. E, principalmente, desconsiderou a própria Constituição brasileira.

Dois cientistas, responsáveis pela área ambiental junto à comissão, discordaram da decisão final da CTNBio, considerando que não havia informações relevantes sobre a interação planta/ambiente nas condições brasileiras, nem sobre o comportamento e as características dos cultivos de soja Roundup Ready plantadas no país. A empresa proponente baseava suas informações unicamente na soja cultivada nos Estados Unidos (CAMÂRA DOS DEPUTADOS, 2000).

Mesmo assim, a comissão aprovou a soja transgênica para comercialização. Em desacordo com essa avaliação improcedente, entidades da sociedade civil recorreram à Justiça e obtiveram decisão favorável a seu pleito. Em função dessa decisão judicial, transcorridos mais de quatro anos do parecer conclusivo da CTNBio, o plantio não se efetivou. Estabeleceu-se, em contrapartida, uma grande polêmica em torno da questão, que revelou diversas contradições nas políticas públicas, ao que se soma a carência de canais de informação para a população em geral, condizentes com a importância social e econômica que o tema encerra.

\section{CONCLUSÕES}

Não se trata de rejeitar a tecnologia dos transgênicos. Tal postura seria indefensável e colocaria o país à margem do progresso científico e da possibilidade de resolver, no futuro, problemas que afetam a população. Ao contrário, é prioritária uma política de fomento às investigações de universidades e institutos tecnológicos que tenham por objetivo o melhor aproveitamento da expressiva biodiversidade brasileira, de modo que o conhecimento produzido redunde na geração de patentes e se evite a apropriação estrangeira dessa riqueza.

Alguns parâmetros fundamentais deveriam, no entanto, pautar a aceitação da biotecnologia agrícola. Além da realização prévia de estudos científicos conclusivos que assegurem a ausência de riscos ambientais e para a saúde, bem como a preservação dos recursos naturais - em consonância com as premissas básicas de uma prática agrícola ecologicamente sustentável -, é imprescindível ponderar suas repercussões econômicas, tanto para os agricultores como para o conjunto do país.

$\mathrm{O}$ arcabouço legal brasileiro relativo à biossegurança era bastante amplo, contendo um conjunto de medidas adequadas a serem observadas por instituições e empresas que realizem atividades envolvendo transgênicos. No entanto, as instâncias governamentais responsáveis não conseguiram assegurar seu cumprimento, adotando uma postura negligente no estabelecimento das exigências técnicas legais.

A Política Nacional de Biossegurança, uma das atribuições da CTNBio, conforme determinou a Lei de Biossegurança de 1995, não foi elaborada. Careceu-se de instruções normativas concernentes, entre outros aspectos, às dimensões aceitáveis das áreas para liberação experimental. Entretanto, mesmo na ausência de diretrizes claras, foram concedidas liberações com OGMs no meio ambiente, em áreas cuja extensão varia de 0,006 a 110 hectares para um mesmo transgênico e com idêntica finalidade. É impossível deduzir quais critérios científicos justificariam tal dispa- 
ridade. Decisões igualmente irresponsáveis encontram-se nas várias liberações de experimentos para "fins de demonstração", chegando uma mesma concessão a contemplar mais de 40 diferentes fazendas particulares. Desse cenário caótico, emergia uma total desconexão entre o trabalho das diversas instâncias envolvidas com a questão da biossegurança dos transgênicos no país. Os Ministérios eximiam-se da fiscalização e assistiam, sem intervir, as constantes liberações por parte da CTNBio. Entretanto, a comissão, mesmo ciente da ausência de fiscalização, prosseguia nas autorizações para experimentos no meio ambiente.

Essa ausência de critérios explícitos para o deferimento de liberações experimentais no meio ambiente, bem como a omissão dos órgãos de vigilância e fiscalização, poderá constituir a gênese de eventuais danos ao meio ambiente. Se a dimensão e as possibilidades de reversão desses danos configuram desafios ao estabelecimento de previsões irrefutáveis, sua ocorrência certamente imporá a todos - críticos ou adeptos da decisão tomada - um imponderável ônus.

Tais omissões, inclusive, tornaram-se fato consumado: aflorou a situação criada pelo plantio, sem nenhum controle estatal, de soja transgênica no país. Diante desse fato consumado e previsível, o atual governo, sob argumentos de ordem eminentemente econômica - não desprezíveis, mas certamente também não incontestáveis - valendo-se de uma medida provisória, liberou a comercialização dessa soja para consumo interno e exportação. Ao interromper abruptamente um processo que ainda mantinha, mesmo que com base numa decisão judicial, a possibilidade de contemplar o Princípio da Precaução, reforçam-se as premissas que vêm sustentando a repetida tolerância com ações que ferem a legalidade.

Em fevereiro de 2003, a Câmara dos Deputados aprovou o Projeto de Lei n. 2.401/03, que substituirá, se aprovado pelo Senado, a legislação de biossegurança atual, estabelecida em 1995. Tal projeto, embora implicando alterações significativas à legislação vigente, não se mostra, até o presente momento, como instrumento capaz de amenizar a discordância entre os diversos atores envolvidos com a temática.

\section{REFERÊNCIAS BIBLIOGRÁFICAS}

ASSOCIAÇÃO alerta para plantio ilegal de transgênicos. Agência Estado, São Paulo, 26 dez. 2001.
BRASIL. Audiência Pública $n^{\circ}$ 000609/01, 21/06/01. Notas Taquigráficas. Brasília, DF: Câmara dos Deputados. Comissão de Defesa do Consumidor, Meio Ambiente e Minorias, 2001. Diário Oficial da União, 188. Brasília, DF, 1 out. 1998. Seção 3, p. 56. Disponível em: <http://www.ctnbio.gov.br/ctnbio/ legis/comunicados/054.htm>. Acesso em: 23 nov. 1999.

CÂMARA DOS DEPUTADOS. Proposta de Fiscalização e Controle n. 34, de 2000: Relatório Final. Documento 201037.00.032. Brasília, DF, Comissão de Defesa do Consumidor, Meio Ambiente e Minorias, 2000.

CAMPANHA por um Brasil livre de transgênicos. Boletim 64, 14 maio 2001. Disponível em: <http://www.dataterra.org.br/Boletins/ aspta64.htm>. Acesso em: 18 jul. 2001.

CIDADANIA/TRANSGÊNICOS - Licenciamento no Brasil. Revista Consumidor S.A., ago./set. 2002.

COMISSÃO TÉCNICA NACIONAL DE BIOSSEGURANÇA CTNBIO. WebSite oficial, 2002. Disponível em: $<$ http://www.ctnbio.gov.br >. Acesso em: 15 fev. 2002.

CTNBIO admite falha na fiscalização de transgênicos no país. Valor Econômico, São Paulo, 22 jun. 2001. Disponível em: $<\mathrm{http}: / /$ www.valor.com.br/valoreconomico/ materia.asp?id=688076>. Acesso em: 13 ago. 2001.

FONTES, E.G.; SUJII, E. R.; BATISTA, M. de F.; FONSECA, J.N.L. Biossegurança. Biodiversidade: perspectivas e oportunidades tecnológicas. Base de Dados Tropical. BDT. 16 ago. 2000. Disponível em: < http://www.bdt.fat.org.br/publicacoes/padct/bio/ cap5/index.html >. Acesso em: 03 mar. 2001.

HOBSBAWN, E. A era dos extremos - o breve século XX. São Paulo: Companhia das Letras, 1995.

LUCRO líquido global da Monsanto tem alta de $5 \%$ no trimestre. Valor Econômico, São Paulo, 26 jul. 2001.

MINISTÉRIO DO MEIO AMBIENTE. Comissão do MMA vai analisar transgênicos. InforMMA de hoje, 2002. Disponível em: $<$ http://www.ambiente.gov.br>. Acesso em: 18 out. 2002.

MINISTRO exige análise ambiental de transgênicos. $O$ Estado de S.Paulo, São Paulo, 25 jul. 2000.

MONSANTO down on Brazil news. Yahoo Finance, 10 ago. 2001. Disponível em: <http://finance.yahoo.com>. Acesso em: 11 ago. 2001 .

PRATINI diz que vai liberar soja transgênica. O Estado de S.Paulo, São Paulo, 21 ago. 2001a. Disponível em: $<$ http://www.estado.estadao.com.br/editorias/2001/07/21/ ger014.html>. Acesso em: 22 ago. $2001 \mathrm{a}$.

PRATINI diz que soja transgênica depende da Justiça. Agência Estado, São Paulo, 08 ago. 2001b.

VIGNA, E. A farra dos transgênicos. Argumento, 5, 2001.

WOLF, M. Teorias da comunicação. Lisboa: Ed. Presença, 1997.

ZAHLER, P.M. Fiscalização e monitoramento do Ministério da Agricultura e do Abastecimento: entrevista. Biotecnologia, Ciência \& Desenvolvimento, n. 3, p. 30-31, 1997.

Carmem L.C. Marinho: Bióloga, Pesquisadora do Centro de Estudos da Saúde do Trabalhador e Ecologia Humana, Escola Nacional de Saúde Pública (cmarinho@ensp.fiocruz.br).

Carlos Minayo-Gomez: Sociólogo, Pesquisador do Centro de Estudos da Saúde do Trabalhador e Ecologia Humana, Escola Nacional de Saúde Pública (minayogo@ensp.fiocruz.br). 